\title{
Efficiency of a formulated condiment (duqqa) in mitigation of diabetes and its complications induced by streptozotocin- nicotinamide in rats
}

\author{
Rasha S. Mohamed ${ }^{1+\mathbb{(})}$, Ahmed M. Abdel-Salam ${ }^{2}$ \\ ${ }^{1}$ Nutrition and Food Sciences Department, National Research Centre, Dokki, Cairo, Egypt \\ ${ }^{2}$ Dairy Science Department, National Research Centre, Dokki, Cairo, Egypt
}

\section{A R T I C L E I N F O}

Article Type:

Original Article

\section{Article History:}

Received: 1 June 2020

Accepted: 25 August 2020

\section{Keywords:}

Type 2 diabetes

Streptozotocin

Nicotinamide

Duqqa

Diabetes complications.

\begin{abstract}
A B S T R A C T
Introduction: Duqqa is a condiment, consisting of black pepper, cumin, sesame, coriander and high amount of salt. Reducing salt and adding other beneficial items to traditional duqqa can make it suitable dietary supplement for diabetes management. The current study aimed to assess the effect of a modified duqqa on diabetes and its complications in diabetic rats.

Methods: The modified duqqa was formulated by mixing grounded fermented wheat, sesame, coriander, cumin, chicory leaves, cinnamon, turmeric and date seeds powder and studied in diabetic rats which were developed by streptozotocin-nicotinamide injection. Thirty-two rats were divided into four groups $(n=8)$ including non-diabetic, diabetic control and the other two groups fed on balanced diet supplemented with either 10 or $20 \%$ of duqqa prior the induction of diabetes (for one week) to the end of the experiment (8 weeks).

Results: The dietary supplementation with 10 and $20 \%$ of the formulated duqqa prior the induction of diabetes did not delay the onset of diabetes in rats but produced reduction (32.56\% and $50.47 \%$, respectively) in the glucose levels of diabetic rats. Also, diabetic rats fed on the formulated duqqa showed insulin concentrations higher than that of diabetic control rats. Feeding diabetic rats on the formulated duqqa reversed the elevation of kidney lipid peroxidation and nitric oxide, limited the disturbance in the lipid profile as well as liver and kidney functions and elevated both serum and femur magnesium concentrations.

Conclusion: The results indicated the hypoglycemic effect of the formulated duqqa and its efficiency in delaying diabetes complications.
\end{abstract}

Implication for health policy/practice/research/medical education:

The formulated duqqa can be served as hypoglycemic condiment and potent protective agent against diabetes complications.

Please cite this paper as: Mohamed RS, Abdel-Salam AM. Efficiency of a formulated condiment (duqqa) in mitigation of diabetes and its complications induced by streptozotocin-nicotinamide in rats. J Herbmed Pharmacol. 2021;10(2):218-225. doi: 10.34172/jhp.2021.24.

\section{Introduction}

Type 2 diabetes mellitus, the heterogeneous metabolic disorders, is identified by hyperglycemia as a result of insulin secretion deficiency or insulin action defect. The prolonged hyperglycemia is associated with increasing reactive oxygen species (ROS) which results in oxidative stress (1). Hyperglycemia accompanied with oxidative stress catalyzes the detrimental pathways of polyol, protein kinase $\mathrm{C}$, advanced glycation end products and hexosamines which result in redox imbalance, modification of gene expression and altered transcription factors which further increase oxidative stress (2). The uncontrolled hyperglycemia and oxidative stress are related to specific microvascular complications influencing the eyes, kidneys and nerves in addition to an expanded hazard for cardiovascular disease (3). The number of people with diabetes in 2017 was estimated at around 451 million worldwide and the prevalence of diabetes is expected to increase to 693 million by 2045 (4).

The burden of diabetes is not limited to its symptoms and complications only, but also the diabetes' treatment is a financial burden, especially in low-income countries (5). 
Alternative and complementary plant-derived therapies may be a good choice to reduce not only the cost of using conventional medications (including hypoglycemic drugs and insulin) but also the side effects of these medications.

Duqqa or dukkah is a condiment, which consists of salt, black pepper, ground cumin, sesame and coriander. Commonly it is eaten in Egypt besides bread. Although it is of Egyptian origin, its good taste made it spread in several other countries.

In the current study, an attempt has been made to assess the effect of a modified duqqa as popular and cheap condiment on diabetes and to evaluate its complications in diabetes rat model.

\section{Materials and Methods}

Materials

Plant materials, sesame (Sesamum indicum), coriander (Coriandrum sativum), cumin (Cuminum cyminum), cinnamon (Cinnamomum verum), black pepper (Piper nigrum), turmeric (Curcuma longa), date palm (Phoenix dactylifera) seed powder, wheat (Triticum aestivum) and chicory leaves (Cichorium intybus) were obtained from local market, Giza, Egypt. Starter cultures of Streptococcus thermophilus, Lactobacillus acidophilus and Lactobacillus plantarum were obtained from Chr. Hansen's Laboratory, Copenhagen, Denmark. Chemicals and pure reagents were purchased from Sigma (Sigma-Aldrich, St. Louis, MO, USA).

\section{Animals}

Adult male Wistar rats weighing $196.69 \pm 12.3 \mathrm{~g}$ as mean \pm SD (11 weeks old) were used. Animals were provided by the animal house of National Research Centre, Cairo, Egypt. The animals were kept individually in stainless steel metabolic cages at room temperature $\left(24 \pm 2^{\circ} \mathrm{C}\right.$ and 40\%-60\% relative humidity) under 12 hours light and dark cycles and allowed free access to food and water. All animals' procedures were carried out according to the Medical Research Ethics Committee, National Research Centre, Cairo, Egypt, and followed the recommendations of the National Institutes of Health Guide for Care and Use of Laboratory Animals (Publication No. 85-23, revised 1985).

\section{Methods}

Preparation of common dried fermented wheat-milk mixture (Kishk)

Buffalo's milk was fermented by the starter cultures. Wheat grains (Triticum aestivum) were cooked in boiled water and sun-dried, then cracked to obtain crushed wheat that was added to the fermented buffalo's milk with the ratio of 1:2 w/w with mixing to prepare kishk dough. Salt $(1.5 \%)$ was added and the dough was incubated at room temperature for one day, then formed into small balls and dried in hot air oven at $50^{\circ} \mathrm{C}$ for 24 hours.

\section{Preparation of duqqa}

Traditional duqqa is a condiment, which consists of high amount of salt, black pepper, ground cumin and sesame. In this study, the modified duqqa (Figure 1) was formulated by mixing grounded fermented Kishk (150 g), sesame (200 g), coriander (200 g), cumin (200 g), chicory leaves $(70 \mathrm{~g})$, cinnamon $(70 \mathrm{~g})$, turmeric $(70 \mathrm{~g})$, date seeds $(15 \mathrm{~g})$, salt $(15 \mathrm{~g})$ and black pepper $(10 \mathrm{~g})$ to form one kilogram of duqqa.

\section{Proximate analysis of duqqa}

The proximate analysis (moisture, ash, crude fat, crude fiber and nitrogen content) was carried out according to the methods of (6). Moisture was determined in an air dryer oven at $105^{\circ} \mathrm{C}$ for 3 hours and the dried weight was recorded after the constant weight. Ash was determined by ignition of the sample in a muffle furnace at $600^{\circ} \mathrm{C}$ until in which it was carbon free. Crude fat was extracted in Soxhlet apparatus using diethyl ether. Crude fiber was determined as residue after acid digestion followed by alkali digestion. Nitrogen content was determined by Kjeldahl method and used in the calculation of protein.

\section{Preparation of animals' diets}

Balanced diet, minerals and vitamin mixtures were prepared as in Table 1 in accordance with AIN-9 (7). Ten and twenty grams from duqqa were mixed with the balanced diet to give diets supplemented with $10 \%$ and $20 \%$ of duqqa respectively. The contents of protein, fat, crude fiber and carbohydrate of the 10 and $20 \mathrm{~g}$ duqqa were reduced from casein protein, corn oil, cellulose and starch.

\section{Induction of diabetes}

Diabetes was induced by single intraperitoneal injection $(60 \mathrm{mg} / \mathrm{kg}$ ) of streptozotocin (STZ, from Sigma Chemical Co.) dissolved in $0.1 \mathrm{M}$ cold citrate buffer ( $\mathrm{pH} 4.5)$ with a pre-nicotinamide $(120 \mathrm{mg} / \mathrm{kg})$ injection to reduce pancreatic destruction (8). The onset of diabetes was confirmed from the higher level of fasting blood glucose (FBG) using a glucometer (One Touch, LifeScan, Zug, Switzerland) after 72 hours of STZ injection. The animal's tail vein was pricked to collect blood for the FBG determination. Animals with FBG above $200 \mathrm{mg} / \mathrm{dL}$ were marked as diabetic.

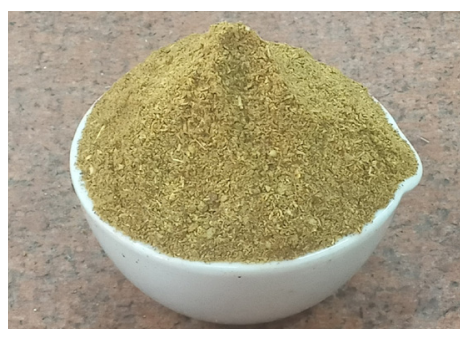

Figure 1. Formulated duqqa (dukka). 
Table 1. Composition of the prepared animals' diets ( $\mathrm{g} / 100 \mathrm{~g})$

\begin{tabular}{lccc}
\hline \multirow{2}{*}{ Ingredients } & \multicolumn{3}{c}{ Diets } \\
\cline { 2 - 4 } & Balanced & 10\% duqqa & 20\% duqqa \\
\hline Protein & $12.00 *$ & 10.32 & 8.64 \\
Casein & & & \\
Fat & 10.00 & 6.61 & 3.23 \\
Corn oil & & & \\
Carbohydrate & 10.00 & 10.00 & 10.00 \\
Sucrose & 58.5 & 54.75 & 50.99 \\
Starch & 3.50 & 3.50 & 3.50 \\
Minerals mixture & 1.00 & 1.00 & 1.00 \\
Vitamin mixture & 5.00 & 3.82 & 2.64 \\
Cellulose (fiber) & - & 10.00 & - \\
10\% duqqa & - & - & 20.00 \\
$20 \%$ duqqa & & & \\
\hline
\end{tabular}

* $12 \mathrm{~g}$ casein has been estimated to contain $10 \mathrm{~g}$ protein. $10 \mathrm{~g}$ of duqqa provided $1.68 \mathrm{~g}$ protein, $3.39 \mathrm{~g}$ fat, $1.18 \mathrm{~g}$ fiber and $2.65 \mathrm{~g}$ carbohydrate and $20 \mathrm{~g}$ of duqqa provided $3.36 \mathrm{~g}$ protein, $6.77 \mathrm{~g}$ fat, $2.36 \mathrm{~g}$ fiber and 5.30 g carbohydrate.

\section{Design of the animals study}

Thirty-two rats were divided after one week acclimatization into four groups (8 rats in each group) as follows:

- G1: non-diabetic group was considered as the control group where rats received a balanced diet.

- G2: diabetic control group where rats induced by diabetes at the $8^{\text {th }}$ day of the experiment and fed on balanced diet.

- G3: diabetic + $10 \%$ duqqa where rats fed on balanced diet supplemented with $10 \%$ of duqqa from the first day to the last day of the experiment and were induced diabetic at the $8^{\text {th }}$ day of the experiment.

- G4: diabetic + $20 \%$ duqqa where rats fed on balanced diet supplemented with $20 \%$ of duqqa from the first day to the last day of the experiment and were induced diabetic at the $8^{\text {th }}$ day of the experiment.

During the experiment, urine volume as well as water and food intake were recorded daily. After 8 weeks (end of the experiment) total food intake, body weight gain and feed efficiency ratio (body weight gain/total food intake) were calculated. Blood samples were collected from all rats after overnight fast then the rats were dissected. Liver, kidney and femur were immediately separated from each rat and weighed. Femur of each rat was burned at $600^{\circ} \mathrm{C}$ using muffle to be converted into ash, which was later used in the estimation of calcium and magnesium.

Biochemical analysis

Serum of each rat was analyzed for insulin (using sandwich ELIZA detection kit, Sinogeneclon Biotech Co., Ltd.), fasting blood glucose levels according to Trinder (9), total cholesterol according to Watson (10), high-density lipoprotein cholesterol (HDL-C) using the method of Burstein et al (11), low-density lipoprotein cholesterol
(LDL-C) according to Schriewer et al (12) and triglyceride according to the method of Megraw et al (13). Cholesterol/ HDL-C ratio was also calculated. The activities of aspartate transaminase (AST) and alanine transaminase (ALT) were determined according to Reitman and Frankel (14). Total protein and albumin were determined according to Rheinhold (15) and Doumas et al (16) in succession. The activity of lactate dehydrogenase (LDH) was determined according to Zimmerman and Weinstein (17). The levels of creatinine and urea were determined depending on Larsen (18) and Fawcett and Scott (19) in succession as indicators of kidney functions. Kidney lipid peroxidation (MDA) and nitric oxide (NO) were determined according to Ohkawa et al (20), and Montgomery and Dymock (21), respectively. Serum magnesium was determined according to Smith (22). Femur calcium and magnesium were determined by the atomic absorption spectrophotometer apparatus (model IL atomic absorption/air ethylene).

\section{Statistical analysis}

Statistical analyses were done using SPSS version 16 . The results were expressed as mean \pm standard error (SE) and analyzed statistically using one-way analysis of variance (ANOVA) followed by Duncan test. The statistical significance of difference was taken at $P \leq 0.05$.

\section{Results}

The formulated duqqa contained 5.62\% moisture, $16.80 \%$ protein, $33.87 \%$ fat, $5.43 \%$ ash, $11.82 \%$ crude fiber and $26.46 \%$ carbohydrate (by the difference). Thus $100 \mathrm{~g}$ of formulated duqqa could provide 477.87 calories.

Effect of dietary supplementation with the formulated duqqa on the growth performance parameters

As is observed from Table 2, there were no significant $(P>0.05)$ differences in total food intake between the groups. However, diabetic control group recorded body weight gain and food efficiency ratio significantly $(P \leq 0.05)$ less than those of normal rats group. Diabetic rats fed on balanced diets supplemented with either 10 or $20 \%$ of the formulated duqqa recorded weight gain and food efficiency ratio significantly higher $(P \leq 0.05)$ than those of diabetic control group. Water intake and urine volume of diabetic control rats were significantly higher $(P \leq 0.05)$ than those of normal rats, while water intake and urine volume of the diabetic rats fed on balanced diets supplemented with either 10 or $20 \%$ of the formulated duqqa were significantly less $(P \leq 0.05)$ than those of diabetic control rats.

Effect of dietary supplementation with the formulated duqqa on pancreas weight, glucose and insulin

Figure 2 (A, B and C) illustrates pancreas weight, fasting glucose levels and fasting insulin concentrations respectively of normal and diabetic rats. Diabetic control group recorded the lowest pancreas weight 
Table 2. Growth performance parameters of normal and diabetic groups

\begin{tabular}{|c|c|c|c|c|}
\hline & Normal control & Diabetic control & Diabetic $+10 \%$ duqqa & Diabetic $+20 \%$ duqqa \\
\hline Initial body weight (g) & $196.62^{\mathrm{a}} \pm 2.86$ & $196.75^{a} \pm 5.75$ & $196.75^{a} \pm 3.31$ & $196.62^{\mathrm{a}} \pm 5.61$ \\
\hline Final body weight (g) & $250.62^{c} \pm 3.96$ & $206.37^{\mathrm{a}} \pm 4.08$ & $233.62^{b} \pm 6.25$ & $238.75^{\mathrm{bc}} \pm 3.97$ \\
\hline Body weight gain (g) & $54.00^{\mathrm{b}} \pm 5.38$ & $9.62^{\mathrm{a}} \pm 8.56$ & $36.87^{b} \pm 4.14$ & $42.12^{b} \pm 3.24$ \\
\hline Total food intake (g) & $770.87^{a} \pm 28.64$ & $810.25^{a} \pm 15.27$ & $767.00^{\mathrm{a}} \pm 25.51$ & $779.12^{\mathrm{a}} \pm 18.90$ \\
\hline Food efficiency ratio & $0.07^{c} \pm 0.007$ & $0.01^{\mathrm{a}} \pm 0.010$ & $0.05^{b} \pm 0.005$ & $0.05^{b c} \pm 0.005$ \\
\hline Water intake $(\mathrm{mL} / \mathrm{d})$ & $30.70^{\mathrm{a}} \pm 1.54$ & $82.77^{c} \pm 2.12$ & $52.03^{b} \pm 3.65$ & $51.80^{b} \pm 3.14$ \\
\hline Urine volume $(\mathrm{mL} / \mathrm{d})$ & $8.95^{\mathrm{a}} \pm 1.18$ & $15.06^{b} \pm 1.21$ & $10.12^{\mathrm{a}} \pm 0.74$ & $9.50^{\mathrm{a}} \pm 1.51$ \\
\hline
\end{tabular}

In each row same letters mean non-significant difference; different letters mean the significance among the tested groups. The confidence level is $95 \%$. The data are expressed as mean values \pm standard error.

(0.6 g) when compared to the other groups. The dietary supplementation with either $10 \%$ or $20 \%$ of the formulated duqqa prior the induction of diabetes did not afford any prophylactic effect against streptozotocin-nicotinamide induced diabetes in rats and did not delay the onset of

(A)

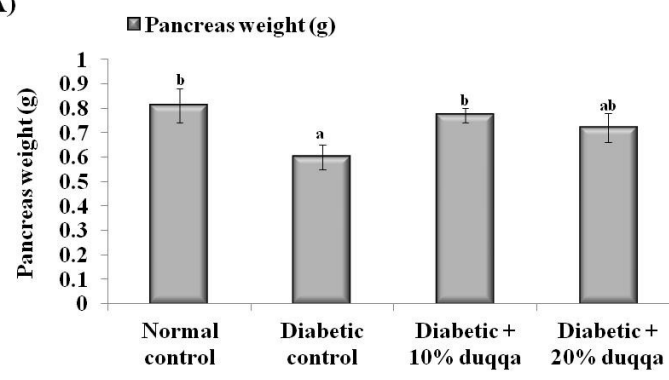

(B)

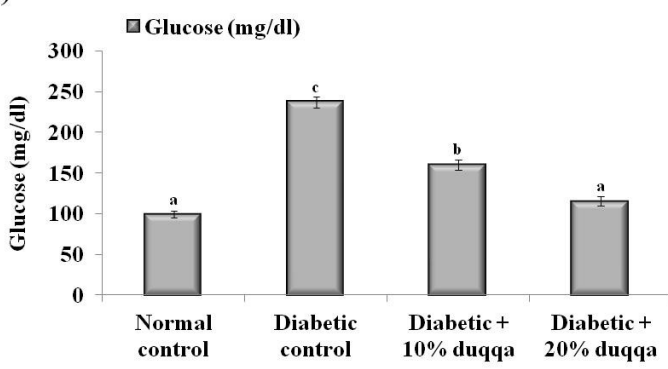

(C)

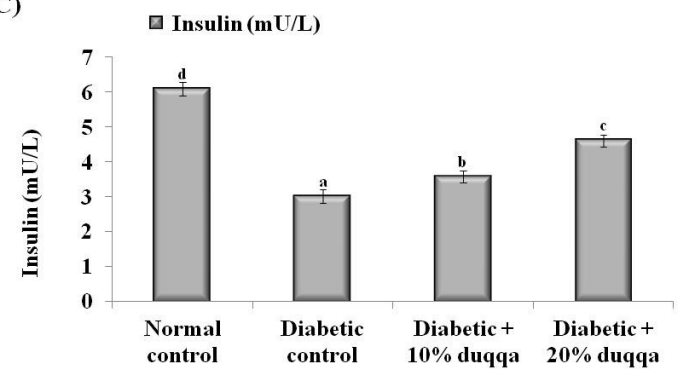

Figure 2. Pancreas weight $(A)$, fasting glucose levels $(B)$ and fasting insulin concentrations $(C)$ of normal and diabetic rats. On bars of each figure (A, B and $C$ ) the same letters mean non-significant difference; different letters mean the significance among the tested groups. The confidence level is $95 \%$. The data are expressed as mean values \pm standard error. diabetes in rats. Glucose level of diabetic control rats $(237.25 \mathrm{mg} / \mathrm{dL})$ were significantly $(P \leq 0.05)$ higher than those of normal rats, while dietary supplementation with 10 and $20 \%$ of the formulated duqqa produced reduction ( 32.56 and $50.47 \%$, respectively) in the glucose levels in comparison to diabetic control group. Insulin concentrations of diabetic control rats $(3.01 \mathrm{mU} / \mathrm{L})$ were significantly less $(P \leq 0.05)$ than those of normal rats. On the other side, dietary supplementation with 10 and $20 \%$ of the formulated duqqa resulted in a rise $(18.6 \%$ and $53.16 \%$, respectively) in the insulin concentrations in comparison to diabetic control group.

Effect of dietary supplementation with the formulated duqqa on lipid profile

As shown in Table 3, cholesterol, triglyceride and LDL-C levels as well as cholesterol /HDL ratio of diabetic control rats were significantly higher $(P \leq 0.05)$ than those of normal rats. Diabetic control group recorded the lowest level of HDL-C $(29.72 \mathrm{mg} / \mathrm{dL})$ when compared to the other groups. On the other side, dietary supplementation with 10 and $20 \%$ of the formulated duqqa suppressed the elevations of cholesterol, triglycerides and LDL-C levels as well as cholesterol/HDL ratio. HDL-C level of diabetic rats fed on balanced diets supplemented with either $10 \%$ or $20 \%$ of the formulated duqqa were significantly higher $(P \leq 0.05)$ than that of diabetic control rats.

Effect of dietary supplementation with the formulated duqqa on liver weight and functions

As shown in Table 4, diabetic control group recorded the highest relative liver weight (3.15\%) when compared to the other groups. AST, ALT and LDH activities of diabetic control rats were significantly higher $(P \leq 0.05)$ than those of normal rats while total protein and albumin concentrations of diabetic control rats were significantly less $(P \leq 0.05)$ than those of normal rats. On the other side, dietary supplementation with $10 \%$ and $20 \%$ of the formulated duqqa suppressed the elevations of AST, ALT and $\mathrm{LDH}$ activities and combated the reductions in total protein and albumin. 
Table 3. Lipid profile of various groups at the end of the experiment

\begin{tabular}{|c|c|c|c|c|}
\hline & Normal control & Diabetic control & Diabetic $+10 \%$ duqqa & Diabetic $+20 \%$ duqqa \\
\hline Cholesterol (mg/dL) & $88.27^{a} \pm 6.20$ & $114.11^{b} \pm 5.32$ & $97.73^{\mathrm{a}} \pm 4.68$ & $91.76^{a} \pm 4.53$ \\
\hline Triglycerides (mg/dL) & $95.95^{\mathrm{a}} \pm 3.15$ & $116.13^{b} \pm 3.08$ & $99.03^{\mathrm{a}} \pm 3.05$ & $94.97^{\mathrm{a}} \pm 2.12$ \\
\hline $\mathrm{HDL}-\mathrm{C}(\mathrm{mg} / \mathrm{dL})$ & $41.45^{\circ} \pm 1.17$ & $29.72^{\mathrm{a}} \pm 0.71$ & $35.00^{\mathrm{b}} \pm 0.82$ & $36.17^{b} \pm 0.77$ \\
\hline LDL-C (mg/dL) & $29.54^{\mathrm{a}} \pm 0.93$ & $61.02^{c} \pm 1.41$ & $39.40^{b} \pm 0.92$ & $36.79^{b} \pm 1.03$ \\
\hline Cholesterol/HDL ratio & $2.13^{\mathrm{a}} \pm 0.14$ & $3.84^{c} \pm 0.14$ & $2.79^{b} \pm 0.13$ & $2.53^{b} \pm 0.10$ \\
\hline
\end{tabular}

In each row the same letters mean non-significant difference; different letters mean the significance among the tested groups. The confidence level is $95 \%$. The data are expressed as mean values \pm standard error. HDL-C: high-density lipoprotein cholesterol; LDL-C: low-density lipoprotein cholesterol.

Table 4. The weight and functions of liver at the end of the experiment

\begin{tabular}{|c|c|c|c|c|}
\hline & Normal control & Diabetic control & Diabetic $+10 \%$ duqqa & Diabetic $+20 \%$ duqqa \\
\hline Liver weight (g) & $5.67^{\mathrm{a}} \pm 0.24$ & $6.47^{b} \pm 0.30$ & $6.19^{\mathrm{ab}} \pm 0.13$ & $6.25^{\mathrm{ab}} \pm 0.22$ \\
\hline Liver relative weight (\%) & $2.26^{\mathrm{a}} \pm 0.08$ & $3.15^{c} \pm 0.19$ & $2.66^{b} \pm 0.07$ & $2.62^{b} \pm 0.09$ \\
\hline $\operatorname{ALT}(\mathrm{U} / \mathrm{I})$ & $28.87^{\mathrm{a}} \pm 0.97$ & $34.50^{c} \pm 1.05$ & $31.87^{b} \pm 0.69$ & $30.50^{\mathrm{ab}} \pm 0.57$ \\
\hline AST (U/I) & $51.50^{\mathrm{a}} \pm 1.25$ & $61.25^{c} \pm 1.30$ & $55.62^{b} \pm 0.92$ & $53.50^{\mathrm{ab}} \pm 1.05$ \\
\hline Total Protein & $7.66^{c} \pm 0.14$ & $5.16^{\mathrm{a}} \pm 0.21$ & $6.12^{b} \pm 0.26$ & $6.40^{b} \pm 0.17$ \\
\hline Albumin & $4.95^{c} \pm 0.10$ & $2.97^{\mathrm{a}} \pm 0.17$ & $3.62^{b} \pm 0.15$ & $4.02^{b} \pm 0.28$ \\
\hline $\mathrm{LDH}$ & $241.00^{\mathrm{a}} \pm 7.06$ & $344.75^{d} \pm 7.43$ & $298.87^{c} \pm 7.36$ & $267.62^{b} \pm 6.63$ \\
\hline
\end{tabular}

In each row the same letters mean non-significant difference; different letters mean significance among the tested groups. The confidence level is 95\%. The data are expressed as mean values \pm standard error. ALT: alanine transaminase; AST: aspartate transaminase; LDH: lactate dehydrogenase.

Effect of dietary supplementation with the formulated duqqa on the kidney weight, functions and oxidative markers

Table 5 presents kidney weight, functions and oxidative markers of normal and diabetic groups. Significant $(P \leq 0.05)$ elevations of kidney relative weight, creatinine, urea, MDA and NO were observed in the diabetic control rats in comparison to normal rats. Dietary supplementation with $10 \%$ and $20 \%$ of the formulated duqqa suppressed the elevations of creatinine and urea concentrations. Also, MDA and NO significantly decreased in diabetic rats fed on balanced diets supplemented with either $10 \%$ or $20 \%$ of the formulated duqqa.

Effect of dietary supplementation with the formulated duqqa on serum and femur electrolytes

No significant difference in the serum magnesium was found between normal and diabetic control groups (Table 6) while serum magnesium significantly increased in diabetic rats fed on balanced diets supplemented with either $10 \%$ or $20 \%$ of the formulated duqqa. Diabetic control group recorded the lowest femur weight $(0.64 \mathrm{~g})$ and femur magnesium concentration $(2.91 \mathrm{mg} / \mathrm{g})$ when compared to the other groups. Also, slight decrease (nonsignificant) in femur calcium concentration was observed in diabetic control rats. Femur magnesium concentrations of diabetic rats fed on balanced diets supplemented with either $10 \%$ or $20 \%$ of the formulated duqqa were significantly $(P \leq 0.05)$ higher than that of diabetic control rats.

\section{Discussion}

In view of the fact that type 2 diabetes and its complications are prevalent (23) and can be managed using plant-

Table 5. Kidney weight, functions and oxidative markers of various groups at the end of the experiment

\begin{tabular}{|c|c|c|c|c|}
\hline & Normal control & Diabetic control & Diabetic $+10 \%$ duqqa & Diabetic $+20 \%$ duqqa \\
\hline Kidney weight (g) & $1.50^{\mathrm{a}} \pm 0.05$ & $1.70^{\mathrm{a}} \pm 0.10$ & $1.54^{\mathrm{a}} \pm 0.07$ & $1.55^{\mathrm{a}} \pm 0.03$ \\
\hline Kidney relative weight (\%) & $0.60^{\mathrm{a}} \pm 0.08$ & $0.83^{b} \pm 0.06$ & $0.66^{\mathrm{a}} \pm 0.04$ & $0.65^{a} \pm 0.02$ \\
\hline Creatinine (mg/dL) & $0.43^{a} \pm 0.03$ & $0.81^{c} \pm 0.03$ & $0.56^{b} \pm 0.02$ & $0.51^{b} \pm 0.02$ \\
\hline Urea (mg/dL) & $25.76^{a} \pm 0.76$ & $34.69^{c} \pm 0.95$ & $28.89^{b} \pm 1.13$ & $26.66^{\mathrm{ab}} \pm 0.93$ \\
\hline MDA (nmol/g tissue) & $11.82^{\mathrm{a}} \pm 0.73$ & $18.05^{\mathrm{b}} \pm 1.34$ & $14.50^{\mathrm{a}} \pm 0.92$ & $13.31^{\mathrm{a}} \pm 0.94$ \\
\hline NO (umol/g tissue) & $52.94^{\mathrm{a}} \pm 2.59$ & $66.61^{b} \pm 4.59$ & $60.07^{\mathrm{ab}} \pm 2.37$ & $56.14^{\mathrm{a}} \pm 3.32$ \\
\hline
\end{tabular}

In each row the same letters mean non-significant difference; different letters mean the significance among the tested groups. The confidence level is $95 \%$. The data are expressed as mean values \pm standard error. MDA: malondialdehyde; NO: nitric oxide. 
Table 6. Serum magnesium as well as femur weight and electrolytes of groups at the end of the experiment

\begin{tabular}{|c|c|c|c|c|}
\hline & Normal control & Diabetic control & Diabetic + $10 \%$ duqqa & Diabetic $+20 \%$ duqqa \\
\hline Serum magnesium (mg/dL) & $3.09^{\mathrm{a}} \pm 0.10$ & $3.02^{\mathrm{a}} \pm 0.09$ & $3.51^{b} \pm 0.13$ & $4.02^{c} \pm 0.15$ \\
\hline \multicolumn{5}{|l|}{ Femur } \\
\hline Weight (g) & $0.79^{b} \pm 0.04$ & $0.64^{\mathrm{a}} \pm 0.01$ & $0.78^{b} \pm 0.03$ & $0.84^{b} \pm 0.02$ \\
\hline Relative weight (\%) & $0.32^{\mathrm{ab}} \pm 0.02$ & $0.31^{\mathrm{a}} \pm 0.01$ & $0.33^{a b} \pm 0.01$ & $0.35^{b} \pm 0.01$ \\
\hline Magnesium (mg/g) & $4.03^{c} \pm 0.12$ & $2.91^{\mathrm{a}} \pm 0.06$ & $3.14^{\mathrm{ab}} \pm 0.10$ & $3.35^{b} \pm 0.18$ \\
\hline Calcium (mg/g) & $282.58^{\mathrm{a}} \pm 7.06$ & $258.12^{\mathrm{a}} \pm 9.92$ & $273.52^{\mathrm{a}} \pm 8.91$ & $280.91^{\mathrm{a}} \pm 7.01$ \\
\hline
\end{tabular}

In each row the same letters mean non-significant difference; different letters mean significance among the tested groups. The confidence level is $95 \%$. The data are expressed as mean values \pm standard error.

derived therapies (2), this study has been intended to assess the effect of formulated duqqa as popular and cheap condiment on diabetes and its complications in streptozotocin- nicotinamide induced diabetic rat model. In the current study, the traditional duqqa (salt, ground cumin, sesame and coriander) was formulated with modification via reducing salt and adding some other ingredients (ground chicory leaves, cinnamon, date seed powder and fermented wheat) to maximize its effects on diabetes and subsequent complications.

Injection with nicotinamide prior streptozotocin has been demonstrated to induce experimental type 2 diabetes in rat since nicotinamide is considered partially safeguard from the damage effect of streptozotocin on pancreatic B-cells which secrete insulin (24). The entrance of streptozotocin into B-cells through the glucose transporter GLUT2 results in DNA damage which causes increased activity of poly (ADP-ribose) polymerase (PARP-1). The excessive activity of this enzyme causes depletion of intracellular $\mathrm{NAD}^{+}$and ATP, thus insulin-secreting cells succumb to necrosis. While nicotinamide inhibits this enzyme and partially protects insulin-secreting cells (25). Indeed, in the current study, streptozotocin- nicotinamide induced hyperglycemia and hypoinsulinemia.

The reduction in body weight gain of diabetic control in addition to the increase of water and food intake occurred owing to hyperglycemia. Kajal and Singh (1) mentioned that hyperglycemia is associated with increased food and water intake as well as muscles loss and protein catabolism which result in body weight loss. In the current study, water intake and urine volume were found to be decreased in the rats fed on the formulated duqqa, which may be due to the hypoglycemic effect of the formulated duqqa. The hypoglycemic effect of the formulated duqqa is attributed to their ingredients. Cumin seeds afford hypoglycemic effect in diabetic rats due to their content of volatile oil, fiber, niacin, copper and other bioactive compounds $(26,27)$. Also, cumin extracts decreased glycosylated hemoglobin in diabetic patients (28). It was proved that coriander seeds extract had hypoglycemic effect in streptozotocin-nicotinamide diabetic rat model in addition to its ability to increase insulin release from pancreas due to the presence of linalool and other active constituents (1) such as flavonoids, polyphenols, $\beta$-carotenoids, tannins, monounsaturated fatty acids and polyunsaturated fatty acids (29) which may contribute to the hypoglycemic effect of the formulated duqqa. Sesame seeds also contributed in the hypoglycemic effect of duqqa due to their content of some anti-diabetic lignans such as sesamin (30), phenolic compounds and dietary fibers (31). Sesame oil exhibited anti-diabetic effect, mitigated the oxidative stress and safely showed synergistic effect with hypoglycemic drugs (32). Fermented wheat was fermented using the lactic acid bacteria that are responsible for the fermentation process and production of vitamins, antioxidants biologically active peptides and other beneficial compounds during the fermentation process, which may be useful in reducing cholesterol and high blood glucose (33). Additionally, the hypoglycemic effect of the formulated duqqa is attributed to chicory leaves that contain inulin and chicoric acid. Peng et al (34) reported that chicoric acid could stimulate the insulin-independent glucose uptake and phosphorylation of protein kinase B (Akt).

It was found in a previous study that injection with streptozotocin alone mediated dislipidemia (35). Similarly, in the present work streptozotocin-nicotinamide mediated dislipidemia, this was attributed to the absence or the insufficient of the insulin leading to disturbance of the lipid metabolism (36). The insulin concentration was found to be improved in the rats fed on the formulated duqqa, which may be contributed to preventing dislipidemia and subsequent cardiovascular complications. Sesamin in the sesame seeds is effective in increasing the excretion of cholesterol into bile and regulating the activity of 3-hydroxy-3-methylglutaryl coenzyme A reductase, the key enzyme in cholesterol synthesis (37).

As mentioned in a previous study, injection of streptozotocin is associated with releasing of ROS. Additionally, the persistent hyperglycemia and hyperlipidemia are associated with elevation of ROS and reduction of antioxidant enzymes (35). Oxidative stress and dislipidemia result in chronic kidney disease and nephropathy (38). Thus in the present work, streptozotocinnicotinamide resulted in abnormalities in the liver and kidney functions. The functional abnormalities in albumin, $\mathrm{LDH}$, creatinine and urea may indicate to the onset of nephropathy. Feeding on the formulated duqqa 
suppressed these functional abnormalities which reflect the beneficial role of the formulated duqqa in preventing nephropathy as one of the most common diabetes complications. This beneficial effect of the formulated duqqa may be due to the hypolipidemic and antioxidant effects of phenolic compounds in duqqa ingredients particularly sesame and coriander seeds as well as chicory leaves as confirmed previously (39-42).

Diabetes mellitus is associated with low bone density and increased risk of fracture in patients (43). However, results of the present study revealed that diabetic rats didn't record any changes in femur calcium level but the femur' weight of diabetic rats was less than non-diabetic rats. The serum magnesium levels were found to be elevated in the rats fed on the formulated duqqa, which may be due to the presence of magnesium in wheat and chicory. Also, these contents of magnesium in wheat and chicory may be contributed to the hypoglycemic effects of the formulated duqqa since Morakinyo et al (44) found that magnesium attenuated hyperglycemia and positively stimulated antioxidant defense system.

\section{Conclusion}

The formulated duqqa exhibited hypoglycemic effects in diabetic rats and suppressed the elevation of cholesterol, triglycerides and LDL-Ch as well as liver and kidney functions. Also, diabetic rats fed on the formulated duqqa showed insulin concentrations higher than that of diabetic control rats. Formulated duqqa elevated both serum and femur magnesium concentration. Hence, the formulated duqqa may be a suitable dietary supplement for diabetes management.

\section{Authors' contributions}

Designing the study was done by RSM and AMA. AMA prepared the fermented wheat and formulated duqqa. RSM performed the proximate analysis, animal experiment, analysis of blood and tissue samples and data analysis. RSM and AMA contributed in the preparation of the manuscript, read and approved the final manuscript. RSM submitted the manuscript.

\section{Conflict of interests}

Authors declare no conflict of interests.

\section{Ethical considerations}

The animal experiments were carried out according to the policies of Medical Research Ethics Committee, National Research Centre, Cairo, Egypt and followed the recommendations of the National Institutes of Health Guide for Care and Use of Laboratory Animals (Publication No. 85-23, revised 1985).

\section{Funding/Support}

None.

\section{References}

1. Kajal A, Singh R. Coriandrum sativum seeds extract mitigate progression of diabetic nephropathy in experimental rats via AGEs inhibition. PLoS One. 2019;14(3):e0213147. doi: 10.1371/journal.pone.0213147.

2. Yuan T, Yang T, Chen H, Fu D, Hu Y, Wang J, et al. New insights into oxidative stress and inflammation during diabetes mellitus-accelerated atherosclerosis. Redox Biol. 2019;20:247-60. doi: 10.1016/j.redox.2018.09.025.

3. Punthakee Z, Goldenberg R, Katz P. Definition, classification and diagnosis of diabetes, prediabetes and metabolic syndrome. Can J Diabetes. 2018;42 Suppl 1:S10-S5. doi: 10.1016/j.jcjd.2017.10.003.

4. Cho NH, Shaw JE, Karuranga S, Huang Y, da Rocha Fernandes JD, Ohlrogge AW, et al. IDF Diabetes Atlas: global estimates of diabetes prevalence for 2017 and projections for 2045. Diabetes Res Clin Pract. 2018;138:271-81. doi: 10.1016/j.diabres.2018.02.023.

5. Moucheraud C, Lenz C, Latkovic M, Wirtz VJ. The costs of diabetes treatment in low- and middle-income countries: a systematic review. BMJ Glob Health. 2019;4(1):e001258. doi: 10.1136/bmjgh-2018-001258.

6. Association of Official Analytical Chemists (AOAC). Official Methods of Analysis. 17th ed. Washington, DC: AOAC; 2000.

7. Reeves PG, Nielsen FH, Fahey GC, Jr. AIN-93 purified diets for laboratory rodents: final report of the American Institute of Nutrition ad hoc writing committee on the reformulation of the AIN-76A rodent diet. J Nutr. 1993;123(11):1939-51. doi: 10.1093/jn/123.11.1939.

8. Shirwaikar A, Rajendran K, Barik R. Effect of aqueous bark extract of Garuga pinnata Roxb. in streptozotocinnicotinamide induced type-II diabetes mellitus. J Ethnopharmacol. 2006;107(2):285-90. doi: 10.1016/j. jep.2006.03.012.

9. Trinder P. Determination of blood glucose using an oxidaseperoxidase system with a non-carcinogenic chromogen. J Clin Pathol. 1969;22(2):158-61. doi: 10.1136/jcp.22.2.158.

10. Watson D. A simple method for the determination of serum cholesterol. Clin Chim Acta. 1960;5:637-43. doi: 10.1016/0009-8981(60)90004-8.

11. Burstein M, Scholnick HR, Morfin R. Rapid method for the isolation of lipoproteins from human serum by precipitation with polyanions. J Lipid Res. 1970;11(6):583-95.

12. Schriewer H, Kohnert U, Assmann G. Determination of LDL cholesterol and LDL apolipoprotein B following precipitation of VLDL in blood serum with phosphotungstic acid/MgCl2. J Clin Chem Clin Biochem. 1984;22(1):35-40. doi: $10.1515 /$ cclm.1984.22.1.35.

13. Megraw RE, Dunn DE, Biggs HG. Manual and continuousflow colorimetry of triacylglycerols by a fully enzymic method. Clin Chem. 1979;25(2):273-8.

14. Reitman S, Frankel S. A colorimetric method for the determination of serum glutamic oxalacetic and glutamic pyruvic transaminases. Am J Clin Pathol. 1957;28(1):56-63. doi: 10.1093/ajcp/28.1.56.

15. Reinhold JG. Total protein, albumin and globulin. In: Reiner M, ed. Standard Methods in Clinical Chemistry. vol. 1. New York: Academic Press; 1953. p. 88.

16. Doumas BT, Watson WA, Biggs HG. Albumin standards and the measurement of serum albumin with bromcresol green. Clin Chim Acta. 1971;31(1):87-96. doi: 10.1016/0009- 
8981(71)90365-2.

17. Weinstein HG, Zimmerman HJ. Lactic dehydrogenase activity in human serum. J Lab Clin Med. 1956;48(4):60716.

18. Larsen K. Creatinine assay by a reaction-kinetic principle. Clin Chim Acta. 1972;41:209-17. doi: 10.1016/00098981(72)90513-x.

19. Fawcett JK, Scott JE. A rapid and precise method for the determination of urea. J Clin Pathol. 1960;13(2):156-9. doi: 10.1136/jcp.13.2.156.

20. Ohkawa H, Ohishi N, Yagi K. Assay for lipid peroxides in animal tissues by thiobarbituric acid reaction. Anal Biochem. 1979;95(2):351-8. doi: 10.1016/00032697(79)90738-3.

21. Montgomery HAC, Dymock JF. The determination of nitrite in water. Analyst. 1961;86(102):414-6.

22. Smith AJ. A colorimetric method for the estimation of serum magnesium. Biochem J. 1955;60(3):522-7. doi: 10.1042/bj0600522.

23. Dabelea D, Stafford JM, Mayer-Davis EJ, D’Agostino R Jr, Dolan L, Imperatore G, et al. Association of type 1 diabetes vs type 2 diabetes diagnosed during childhood and adolescence with complications during teenage years and young adulthood. JAMA. 2017;317(8):825-35. doi: 10.1001/ jama.2017.0686.

24. Kishore L, Kajal A, Kaur N. Role of nicotinamide in streptozotocin induced diabetes in animal models. J Endocrinol Thyroid Res. 2017;2(1):555577. doi: 10.19080/ jetr.2017.02.555577.

25. Tyurenkov IN, Kurkin DV, Bakulin DA, Volotova EV, Chafeev MA, Smirnov AV, et al. ZB-16, a novel gPR119 agonist, relieves the severity of streptozotocinnicotinamide-induced diabetes in rats. Front Endocrinol (Lausanne). 2017;8:152. doi: 10.3389/fendo.2017.00152.

26. Tahir HU, Sarfraz RA, Ashraf A, Adil S. Chemical composition and antidiabetic activity of essential oils obtained from two spices (Syzygium aromaticum and Cuminum cyminum). Int J Food Prop. 2016;19(10):2156-64. doi: $\quad$ 10.1080/10942912.2015.1110166.

27. Pandey S, Patel MK, Mishra A, Jha B. Physio-biochemical composition and untargeted metabolomics of cumin (Cuminum cyminum L.) make it promising functional food and help in mitigating salinity stress. PLoS One. 2015;10(12):e0144469. doi: 10.1371/journal.pone.0144469.

28. Mansouri A, Shahraki Vahed A, Shahdadi H, Dashtban F, Arbabisarjou A. The effect of garlic and cumin on blood pressure and glycosylated hemoglobin in patients with type 2 diabetes. Bali Med J. 2018;7(1):15660. doi: 10.15562/bmj. v7i1.849.

29. Hameed S, Arshad MS, Ahmad RS, Hussain G, Imran M, Arshad MU, et al. Potential preventive and protective perspectives of different spice powders and their mixtures in rat model. Lipids Health Dis. 2020;19(1):78. doi: 10.1186/ s12944-020-01223-9.

30. Farbood Y, Ghaderi S, Rashno M, Khoshnam SE, Khorsandi L, Sarkaki A, et al. Sesamin: a promising protective agent against diabetes-associated cognitive decline in rats. Life Sci. 2019;230:169-77. doi: 10.1016/j.lfs.2019.05.071.

31. Ortega-Hernández E, Coello-Oliemans C, OrnelasCravioto A, Santacruz A, Becerra-Moreno A, JacoboVelázquez DA. Phytochemical characterization of sesame bran: an unexploited by-product rich in bioactive compounds. CyTA J Food. 2018;16(1):814-21. doi: 10.1080/19476337.2018.1480534.

32. Gupta RC, Chang D, Nammi S, Bensoussan A, Bilinski K, Roufogalis $\mathrm{BD}$. Interactions between antidiabetic drugs and herbs: an overview of mechanisms of action and clinical implications. Diabetol Metab Syndr. 2017;9:59. doi: 10.1186/s13098-017-0254-9.

33. Şanlier N, Gökcen BB, Sezgin AC. Health benefits of fermented foods. Crit Rev Food Sci Nutr. 2019;59(3):50627. doi: 10.1080/10408398.2017.1383355.

34. Peng Y, Sun Q, Park Y. Chicoric acid promotes glucose uptake and Akt phosphorylation via AMP-activated protein kinase $\alpha$-dependent pathway. J Funct Foods. 2019;59:8-15. doi: 10.1016/j.jff.2019.05.020.

35. Mohamed RS, Marrez DA, Salem SH, Zaghloul $\mathrm{AH}$, Ashoush IS, Farrag ARH, et al. Hypoglycemic, hypolipidemic and antioxidant effects of green sprouts juice and functional dairy micronutrients against streptozotocininduced oxidative stress and diabetes in rats. Heliyon. 2019;5(2):e01197. doi: 10.1016/j.heliyon.2019.e01197.

36. Vergès B. Pathophysiology of diabetic dyslipidaemia: where are we? Diabetologia. 2015;58(5):886-99. doi: 10.1007/ s00125-015-3525-8.

37. Liang YT, Chen J, Jiao R, Peng C, Zuo Y, Lei L, et al. Cholesterol-lowering activity of sesamin is associated with down-regulation on genes of sterol transporters involved in cholesterol absorption. J Agric Food Chem. 2015;63(11):2963-9. doi: 10.1021/jf5063606.

38. Jabarpour M, Rashtchizadeh N, Argani H, Ghorbanihaghjo A, Ranjbarzadhag M, Sanajou D, et al. The impact of dyslipidemia and oxidative stress on vasoactive mediators in patients with renal dysfunction. Int Urol Nephrol. 2019;51(12):2235-42. doi: 10.1007/s11255-019-02319-7.

39. Bopitiya D, Madhujith T. Antioxidant activity and total phenolic content of sesame (Sesamum indicum L.) seed oil. Trop Agric Res. 2015;24(3):296-302. doi: 10.4038/tar. v24i3.8015.

40. Mekky RH, Abdel-Sattar E, Segura-Carretero A, Contreras MDM. Phenolic compounds from sesame cake and antioxidant activity: a new insight for agri-food residues' significance for sustainable development. Foods. 2019;8(10). doi: 10.3390/foods8100432.

41. Yashin A, Yashin Y, Xia X, Nemzer B. Antioxidant activity of spices and their impact on human health: a review. Antioxidants (Basel). 2017;6(3). doi: 10.3390/ antiox6030070.

42. Jancic D, Todorovic V, Sircelj H, Dodevska M, Beljkas B, Znidarcic D, et al. Biologically active compounds and antioxidant capacity of Cichorium intybus L. leaves from Montenegro. Ital J Food Sci. 2017;29(4):627-43. doi: $10.14674 /$ ijfs-789.

43. Murray CE, Coleman CM. Impact of diabetes mellitus on bone health. Int J Mol Sci. 2019;20(19). doi: 10.3390/ ijms20194873.

44. Morakinyo AO, Samuel TA, Adekunbi DA. Magnesium upregulates insulin receptor and glucose transporter- 4 in streptozotocin-nicotinamide-induced type-2 diabetic rats. Endocr Regul. 2018;52(1):6-16. doi: 10.2478/enr-20180002 . 